\title{
Moesin: A Cell Membrane Protein Linked with Susceptibility to Measles Virus Infection
}

\author{
LEE M. DUNSTER, ${ }^{*}, 1$ JÜRGEN SCHNEIDER-SCHAULIES, * SIEGLINDE LÖFFLER, * WOLFGANG LANKES, $†$ \\ REINHARD SCHWARTZ-ALBIEZ, ₹ FRIEDRICH LOTTSPEICH,§ AND VOLKER TER MEULEN* \\ *Institut for Virologie und Immunbiologie, Versbacher Strasse 7, 0-97078 Wurzburg, Germany; +Medizinische Klinik 1, Klinikum der RWTH \\ Aachen, Pauwel Strasse 30, D.52074 Aachen, Germany; ‡Deutsches Krebsforschungszentrum, Im Nevenheimer Feld 280, D-69120 \\ Heidelberg, Germany; and \$Max Planck Institut fur Biochemie, Am Klopferspitz, D-82152 Martinsried, Germany
}

Received fuly 27, 1993; accepted September 17, 1993

\begin{abstract}
Measles virus is a highly contagious virus causing acute and persistent diseases in man, the receptor of which is still not well characterized. We have isolated a monoclonal antibody (mAb), designated mAb 119, which specifically inhibits measles virus infection of susceptible cell lines in a dose-dependent manner. This antibody precipitates a protein with an apparent molecular mass of $75 \mathrm{kDa}$ from ${ }^{125}$ / surface-labeled cells and its epitope is present on human peripheral blood mononuclear cells, human cell lines, and the African green monkey cell line Vero. Affinity chromatography of detergent-solubilized cell membrane proteins over a Sepharose column with covalently bound mAb 119 led to the partial purification of the 75-kDa protein. Preincubation of measles virus with this affinity-purified protein inhibited measles virus infection dose dependently. Amino acid microsequencing of this protein revealed its identity with the human membrane-organizing extension spike protein moesin, a protein intra- and extracellularly associated with the plasma membrane of cells. Subsequently, an antibody raised against purified moesin (mAb 38/87) was also found to specifically inhibit measles virus infection of susceptible cells and confirmed our data obtained with mAb 119. Our data suggest that moesin is acting as a receptor for measles virus. 1994 Academic Press, inc.
\end{abstract}

\section{INTRODUCTION}

Measles virus (MV) is a highly successful pathogen and is responsible for the disease measles, classically a childhood community-related disease. The acute disease, which is largely self-limiting, gives life long immunity to MV, a situation which is aided by the existence of a single immunotype of MV. However, life threatening diseases can occur following exposure to $\mathrm{MV}$ and include acute measles encephalitis, measles inclusion body encephalitis (MIBE), and subacute sclerosing panencephalitis (SSPE), which target the central nervous system with devastating effect. The tropism of the virus in acute measles is directed largely to epithelial cells of the respiratory tract and cells of the immune system, i.e., lymphocytes and macrophages (for review see Casali et al., 1989). By comparison, in brains of SSPE and MIBE patients MV has been detected mainly in neurons, but also in oligodendrocytes, astro. cytes, microglial cells, and endothelial cells (Esiri et al., 1981; Kirk et al., 1991; Haase et al., 1985; Moench et al., 1988; Schneider-Schaulies and ter Meulen, 1992).

As a member of the Morbilliviruses, MV posesses an envelope that surrounds the viral nucleocapsid which contains one copy of a single-stranded negative sense RNA genome. The virus envelope has two virus-encoded glycoproteins inserted into it: the hemagglutinin

\footnotetext{
1 To whom reprint requests should be addressed.
}

(H) protein, which mediates both virus attachment to susceptible cells and the biological activity of hemagglutination, while the fusion (F) protein, in conjunction with MV-H, is responsible for cell entry and fusion (Wild et al., 1991). Natural MV infection is limited to humans, although monkeys can be infected under experimental conditions, thus suggesting the presence of a MV cell receptor that is unique to higher primates.

The primary event for successful infection of a cell by the virus involves attachment to the target cell and subsequent uptake of virus particles. This process is usually, although not exclusively, mediated by a specific virus receptor on the cell surface, which, depending on their distribution, may influence virus tropism (White and Littman, 1989). Viral receptors have been established for a growing number of viruses and recent evidence suggests that many viruses can utilize additional and/or alternative receptors for the attachment to cells (Dveskler et al., 1993; Harouse et al., 1989. 1991; Lentz, 1990; Schneider-Schaulies et al., 1992).

For MV there have been a number of studies performed in an attempt to define its cellular receptor (Krah 1989, 1991; Harrowe et al., 1990, 1992; Yoshikawa et al., 1991). Putative receptors were found to be present on human cells, Vero cells, and monkey erythrocytes and most likely to consist of glycosylated proteins. Identification by gel electrophoresis of the protein species involved in attachment of $M V$ to susceptible cells was, uníortunately, largely inconclusive (Krah. 
1991). However, in a recent study, a monoclonal antibody (mAb) was developed against a specific human cell surface protein which was found to inhibit MV infection (Naniche et al., 1992). The mAb immunoprecipitated a protein with the apparent molecular mass of $57 / 67 \mathrm{kDa}$. The protein, which was designated gp57/ 67. was subsequently identified as the membrane cofactor protein or CD46 (Naniche et al., 1993b). However, CD46 is not present on all cells susceptible to MV infection, suggesting the presence of an additional receptor species. In this study we have characterized a protein which is immunoprecipitated by a mAb, which specifically inhibits to a high degree the infection of a wide range of cells by MV. The immunoaffinity-purified protein binds MV and has been identified as the membrane-organizing extension spike protein, moesin. These data implicate moesin as a further receptor species for attachment and uptake of MV into susceptible cells.

\section{MATERIALS AND METHODS}

\section{Cell culture}

Adherent cell lines (human astrocytoma U-251, human cervical carcinoma HeLa, human neuroblastoma SKN-MC, African green monkey kidney Vero) were propagated and maintained in Eagles minimal essential medium (EMEM) supplemented with $5 \%$ fetal calf serum. Human monocyte cell line U-937 and primary human peripheral blood mononuclear cells (PBMC) were maintained in RPMI 1640 supplemented with $10 \%$ fetal calf serum, $2.0 \mathrm{~g} /$ liter sodium bicarbonate. $0.1 \mathrm{~g} /$ liter penicillin, $0.1 \mathrm{~g} /$ /iter streptomycin, $1 \mathrm{mM}$ sodium pyruvate, nonessential amino acids, BME vitamins and $2 \mathrm{mM} \mathrm{L-glutamine} \mathrm{(all} \mathrm{Seromed).}$

\section{Viruses}

The Edmonston strain of MV was used throughout the experiments with virus stocks prepared according to Schneider-Schaulies et al. (1993). Additional viruses (canine distemper virus CDV, poliovirus serotypes 1, 2, and 3, Coxsackie viruses $B 2$ and $B 4$, and Echovirus 11) were propagated as above, except for the freeze-thaw step which was omitted for the enteroviruses.

\section{Culture and selection of monoclonal antibodies}

Monoclonal antibodies were raised against cell surface epitopes by inoculating BALB/C mice intraperitoneally (i.p.) with $1-2 \times 10^{6} \mathrm{U}-251$ cells. Four weeks later the mice were boosted with a further i.p. inoculation of U-251 cells and followed 1 month later by a final challenge intravenously, 3-4 days prior to harvesting the spleen. BALB/C spleen cells were fused with the myeloma cell line Sp2/0-Ag14 and seeded into 96-well dishes for selection of hybridomas. Hybridoma cells were grown in RPMI 1640 medium as described earlier.

Screening of hybridoma cells for those secreting mAbs that inhibit infection by MV was performed in microtiter plates. Supernatants of hybridoma cultures were added to confluent Vero cells $\left(3 \times 10^{4}\right.$ per well) in microtiter plates $30 \mathrm{~min}$ prior to infection with $\mathrm{MV}$ (m.o.i. $=0.1$ ) and incubated for 2 days at $37^{\circ}$. Inhibition of virus-induced cytopathic effect was observed microscopically. Protein-G column-purified mAbs were stored at $-20^{\circ}$ at a concentration of $1 \mathrm{mg} / \mathrm{ml}$ for use The $\mathrm{mAb} 38 / 87$ raised against the membrane-organizing extension spike protein, moesin, was described (Lankes et al., 1988). Antibodies to MHC class I (W6/ 32) and CD58 (LFA-3) were purchased (Dianova) and mAbs to MV-H (K83), MV-F (A504), and U85 (raised against $U-251$ cells) were prepared in the laboratory and purified over protein-G columns.

\section{Plaque formation inhibition test}

This test was performed on both Vero and U-251 cell monolayers in six-well plastic dishes $\left(1 \times 10^{6}\right.$ cells per well). Confluent cell monolayers were washed with PBS and $100 \mu$ l of hybridoma cell supernatant (clarified by centrifugation at $300 \mathrm{~g}$ for $5 \mathrm{~min}$ ) or specific concentrations of purified antibodies were added. After incubation at room temperature for $45 \mathrm{~min}$, the monolayers were washed once with PBS and $100 \mu$ l of PBS containing $100 \mathrm{PFU}$ of MV was added to each test well. Further incubation at room temperature for $1 \mathrm{hr}$ was followed by washing with PBS prior to overlaying the wells with $5 \mathrm{ml}$ of EMEM supplemented with $1 \%$ fetal calf serum and $1 \%$ Noble agar (Sigma). Plaques were visualized after $3-5$ days of incubation at $37^{\circ}$ by staining with neutral red.

\section{Rosetting assay}

Rosetting assays were made with $10^{5} \mathrm{U}-937$ cells in $100 \mu \mathrm{l}$ culture medium and incubated for $1 \mathrm{hr}$ at $4^{\circ}$ with either mAb 38/87 or mAb 119 or with the control mAbs W6/32 (MHC class 1 specific) and U85 (nonbinding) (all $0.5 \mathrm{mg} / \mathrm{ml}$ ). After washing with PBS, 50 hemagglutinating units of MV was added followed by incubation for 1 $\mathrm{hr}$ at $4^{\circ}$. The cells were washed with PBS and resuspended in $200 \mu$ l PBS containing monkey erythrocytes at a final concentration of $0.1 \%$ and incubated for $1 \mathrm{hr}$ at $37^{\circ}$. Rosettes were defined microscopically as cells with three or more erythrocytes attached to the surface and results normalized to $0 \%$ inhibition against the nonbinding mAb U85.

Inhibition of vaccinia virus MV-H/F-mediated fusion

As an additional rapid screening assay for infection inhibiting $m A b s$ we used a vaccinia virus double recombinant encoding both $\mathrm{MV}-\mathrm{H}$ and $-\mathrm{F}$ proteins $(\mathrm{VV}-\mathrm{H} / \mathrm{F}$, 
Wild et al., 1991; a kind gift from T. F. Wild, Lyon, France). mAbs were screened for their ability to inhibit the rapid and characteristic cell fusion associated with the expression of MV-H and - F proteins. Briefly, cells (U-251, HeLa or Vero) were seeded into 48-well cluster plates $\left(1 \times 10^{6}\right.$ per well) and grown to confluency. The monolayers were washed with PBS and dilutions of mAb supernatant added to each test well and incubated at room temperature for $30 \mathrm{~min}$. After incubation, W-H/F at an m.o.i. of 0.1 PFU was added and incubation for $18 \mathrm{hr}$ at $37^{\circ}$ made before fixing the cell monolayers with $3.5 \%$ paraformaldehyde in PBS and determining the inhibition of syncytium formation under the microscope.

\section{Flow cytometry analysis}

Flow cytometric analysis was performed as described (Schneider-Schaulies et al., 1992). Briefly, $2 \times$ $10^{5}$ cells were incubated for $45 \mathrm{~min}$ on ice with $200 \mu \mathrm{l}$ $\mathrm{mAb}$. Cells were washed three times in FACS buffer (PBS containing $0.4 \%$ BSA and $0.02 \%$ sodium azide) and incubated with $200 \mu$ l of a 1:100 dilution of fluorescein isothiocyanate-conjugated goat anti-mouse immunoglobulin (Dako) on ice for a further $45 \mathrm{~min}$. After three washes with FACS buffer as before, flow cytometric analysis was performed on a FACScan (Becton Dickinson). For intracellular staining of epitopes, cells were fixed and permeabilized prior to application of the first antibody with $3.7 \%$ paraformaldehyde, $0.25 \%$ Triton $X-100$ in PBS for 5 min and unspecific binding was blocked by FACS buffer containing 10\% BSA.

\section{Surface labeling of cells with ${ }^{125}$ |}

Surface iodination of cells $\left(1 \times 10^{7}\right.$ cells $\left./ 500 \mu l\right)$ with $500 \mu \mathrm{Ci}^{125}$ I was performed using the lodogen method and the manufacturers protocol (Pierce). Following iodination, the reaction was quenched with $30 \mathrm{mM}$ sodium iodide after which the cells were washed three times with PBS and resuspended in lysis buffer $(10 \mathrm{mM}$ Tris, $\mathrm{pH} 7.4,150 \mathrm{mM}$ sodium chloride, $0.5 \%$ deoxycholate, $0.5 \%$ Triton $X-100,0.05 \%$ SDS) containing protease inhibitors (10 $U$ aprotinin, $1 \mathrm{mM}$ PMSF). After vigorous mixing for $30 \mathrm{sec}$ and incubation on ice for 15 $\mathrm{min}$, the lysates were centrifuged at $15,000 \mathrm{~g}$ for $30 \mathrm{~min}$ at $4^{\circ}$ and the supernatant was stored at $-70^{\circ}$ for use.

\section{Immunoprecipitations}

Immunoprecipitations were performed according to Schneider-Schaulies et al. (1992) with the following modifications. All lysates were precleared prior to immunoprecipitation by the addition of $5 \mu$ l normal mouse serum and incubated on ice for $1 \mathrm{hr}$. Mouse immunoglobulins were precipitated by adding $30 \mu$ of packed protein A-Sepharose beads (Pharmacia) bound to rabbit anti-mouse immunoglobulins for $30 \mathrm{~min}$ on ice fol- lowed by centrifugation. Precipitates were analyzed by separation on $10 \%$ SDS-containing polyacrylamide gels (SDS-PAGE) and exposure of the dried gels to a phosphor imager (Molecular Dynamics) screen for $16 \mathrm{hr}$.

\section{Cell membrane preparation}

All procedures for the preparation of cell membranes were performed at $4^{\circ}$ in the presence of protease inhibitors to minimize any degradation of sensitive protein structures. Anchorage-dependent cells were removed nonenzymatically from the culture flask with $\mathrm{Ca}^{2+}$ and $\mathrm{Mg}^{2+}$ free PBS plus $1 \mathrm{mM}$ EDTA, while suspension cells were pelleted by low speed centrifugation $(200 \mathrm{~g}$ for $5 \mathrm{~min}$ ). Cells were washed twice with $\mathrm{Ca}^{2+}$ and $\mathrm{Mg}^{2+}$ free PBS before resuspending the pellet in Buffer I $\left(\mathrm{Ca}^{2+}\right.$ and $\mathrm{Mg}^{2+}$ free PBS, $10 \%$ sucrose, 2 mM EDTA, and $1 \mathrm{mM}$ PMSF) and centrifuging for $1 \mathrm{hr}$ at 22,000 $\mathrm{rpm}$ in an SW55 rotor (Beckman) to pellet vesicles. The pellet was gently resuspended in hypotonic Buffer II (50 mM phosphate buffer, $\mathrm{pH} 7.4,1 \mathrm{mM}$ PMSF) and centrifuged for $30 \mathrm{~min}$ at $14,000 \mathrm{rpm}$ in an $\mathrm{SW} 40$ rotor (Beckman) to allow for the increased volume of buffer. The resulting pellet was resuspended in lysis buffer (PBS plus 1.5\% octylglucoside, $1 \mathrm{mM}$ PMSF) at a ratio of $3 \mathrm{ml} / \mathrm{g}$ wet cell mass and incubated on ice for $1 \mathrm{hr}$. The lysate was centrifuged at 35,000 rpm for $1 \mathrm{hr}$ in an SW55 rotor (Beckman), after which the supernatant was carefully removed and dialyzed overnight against PBS with $0.1 \%$ octyl glucoside before aliquoting and storage at $-70^{\circ}$. Total protein concentration was determined using the bicinchoninic acid method (Sigma) with typical yields from $1 \mathrm{~g}$ of wet cell mass equalling $10-15 \mathrm{mg} / \mathrm{ml}$.

\section{Immunoaffinity purification of proteins}

Specific immunoaffinity purification of cell membrane proteins by mAb was achieved using standardized protocols form manufacturers. Protein-G-purified $\mathrm{mAb}$ was linked to activated Sepharose $4 \mathrm{~B}$ beads (Pharmacia) to form an immunoaffinity matrix. Detergent-extracted cell membranes (see above) were then passed over the mAb column at $4^{\circ}$ and bound proteins eluted with a sodium chloride step gradient. The eluted fractions were dialyzed against PBS (for biological analysis) or $10 \mathrm{mM}$ Tris (for biochemical analysis).

\section{Amino acid sequencing}

For direct $\mathrm{N}$-terminal amino acid sequencing, the affinity-purified protein was applied to a $10 \%$ SDS-PAGE gel, separated, and analyzed after electroblotting onto Glassybond (Biometra, Göttingen) according to Eckerskorn et al., 1988. For internal sequencing the protein was cleaved in the gel with protease Lys C (Boehringer, Tutzing), the peptides eluted and separated by reversed-phase HPLC on Superspher 60 RP select B. 


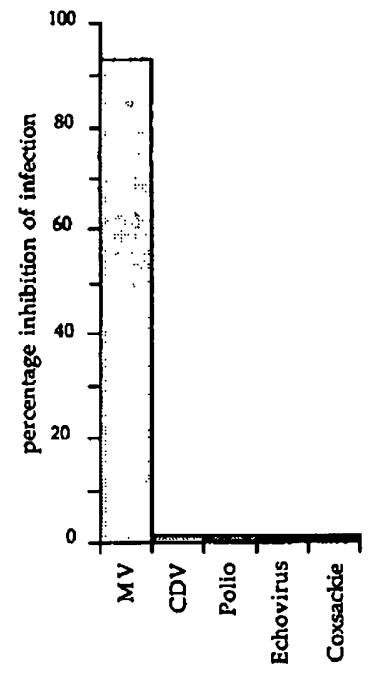

Fig. 1. Inhibition of MV infection by mAb 119. The reduction in virus titer following pretreatment of cell monolayers with mAb 119 was determined by plaque inhibition assay (100 PFU test). The percentage of infectivity was determined by comparison to mocktreated (PBS) cell monolayers for each virus. An inhibition of infection was specifically detected for MV, but not for COV, Polio 1, 2, 3, Echo 11. and Coxsackie B2, B4.

$125 \times 2 \mathrm{~mm}$ (Eckerskorn and Lottspeich, 1989). Amino acid sequence analyses were performed on a $477 \mathrm{~A}$ pulse liquid phase sequencer equipped with a $120 \mathrm{~A}$ PTH analyzer (Applied Biosystems, Weiterstadt).

\section{RESULTS}

\section{Isolation of antibodies inhibiting MV infection}

BALB/C mice were immunized with human astrocytoma cell line U-251, these cells being highly susceptible to infection with MV strain Edmonston and supporting its replication to high titers $\left(10^{6} \mathrm{PFU} / \mathrm{ml}\right)$. Approximately 3000 antibody producing hybridoma clones were assayed for their ability to inhibit MV infection using a rapid infection inhibition test in microtiter plates (see Materials and Methods). One clone which efficiently inhibited MV infection, and also recognized an epitope on the surface of $U-251$ cells as determined by flow cytometry (not shown), was subcloned three times by limiting dilution until a stable antibody producing clone was isolated. The mAb secreted by this clone was designated $\mathrm{mAb} 119$. In the following experiments the $m A b$ was used as a purified fraction from a proteinG column.

Inhibition of MV infection following treatment of cell monolayers with mAb 119 was found to be specific for $\mathrm{MV}$ alone after repeating $100 \mathrm{PFU}$ plaque reduction tests with a number of different viruses. The data in Fig. 1 show that MV infection of Vero cells is inhibited by $92 \%$ after pretreatment of the monolayer with mAb
119. A similar level of inhibition of MV infection (90\%) by mAb 119 was observed on U-251 cells (data not shown). In comparison, no inhibition of virus infection was seen for the related morbillivirus canine distemper virus (CDV), polio serotypes 1, 2, and 3, Echovirus 11, and Coxsackie viruses $\mathrm{B} 2$ and $\mathrm{B} 4$ in similar assays. Therefore, mAb 119 exhibits properties characteristic and coincident with a receptor-blocking antibody and represents an ideal instrument with which to identify the cell surface protein involved in this specific interaction.

\section{Immunoprecipitation of a 75-kDa protein with $\mathrm{mAb}$ 119}

To determine the molecular mass of the putative MV cell receptor molecule, surface proteins of the human monocyte cell line U-937, which expresses high levels of the mAb 119 epitope, were labeled with ${ }^{125}$. MAb 119 precipitated a protein of an apparent molecular weight of $75 \mathrm{kDa}$ from U-937 cells (Fig. 2, lanes 4 and 5). A protein of the same apparent molecular weight could be precipitated from HeLa, U-251, and Vero cells (data not shown). Because the cells were radioiodinated, the protein precipitated by mAb 119 is expected to be expressed on the surface of cells and hence be able to interact with external ligands. By Western blot analysis of U-937 cell lysates, mAb 119 was unable to

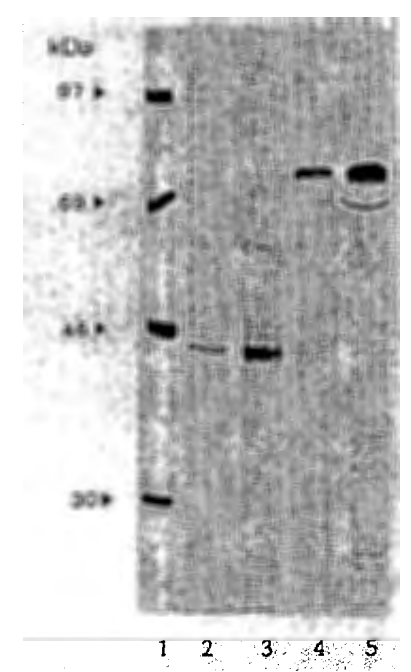

FIG. 2. Immunoprecipitation of ${ }^{125}$ /-labeled cell surface proteins with mAb 119. Cell surface proteins of U-937 cells were iodinated and cell lysates immunoprecipitated with mAb 119 and an antibody to $\mathrm{MHC}$ class I as control. The precipitates were separated by $10 \%$ SDS-PAGE and exposed to a phosphor imager screen for $16 \mathrm{hr}$. Lane $1,{ }^{14} \mathrm{C}$-labeled protein markers: lane 2, U-937 cell lysate precipitated with PBS as negative control; lane 3. U-937 cell lysate precipitated with the MHC class I-specific mAb W6/32; lane 4, U-937 cell lysate precipitated with $\mathrm{mAb} 119(10 \mu \mathrm{g} / \mathrm{ml})$; lane 5 . U937 cell lysate precipitated with mAb $119(100 \mu \mathrm{g} / \mathrm{ml})$. The mAb 119 specifically precipitated a molecule with the apparent molecular mass of 75 kDa. 
detect the $75-\mathrm{kDa}$ protein, suggesting that protein conformation is vital (data not shown).

\section{Affinity purification of putative receptor molecules}

In order to identify the protein precipitated by $\mathrm{mAb}$ 119 by microsequencing and to further characterize it biologically, it was necessary to obtain large amounts of purified protein. To achieve this, mAb 119 was covalently bound to activated Sepharose to form a matrix for affinity chromatography. Detergent (octyl glucoside) solubilized cell membranes from U-937 cells were circulated over the column for $18 \mathrm{hr}$ at $4^{\circ}$ prior to washing the column free of unbound proteins. Elution of bound proteins from the column was achieved using a $\mathrm{NaCl}$ step gradient and the eluate was then further concentrated with polyethylene glycol. The proteins were analyzed by SDS-PAGE and stained with Coomassie blue (Fig. 3). The predominant protein species was eluted with $300 \mathrm{mM} \mathrm{NaCl}$ and possessed the same apparent molecular mass as the immunoprecipitated $(75 \mathrm{kDa})$ protein (Fig. 3, lanes 4 and 6). The yield of purified protein from the immunoaffinity column was typically 200-250 $\mu \mathrm{g}$ per $20 \mathrm{mg}$ total protein loaded.

\section{Biological activity of the enriched $75-\mathrm{kDa}$ protein}

The immunoaffinity-purified protein likely contains a receptor binding motif for MV and by inference should effectively bind $\mathrm{MV}$ in solution, if protein conformation

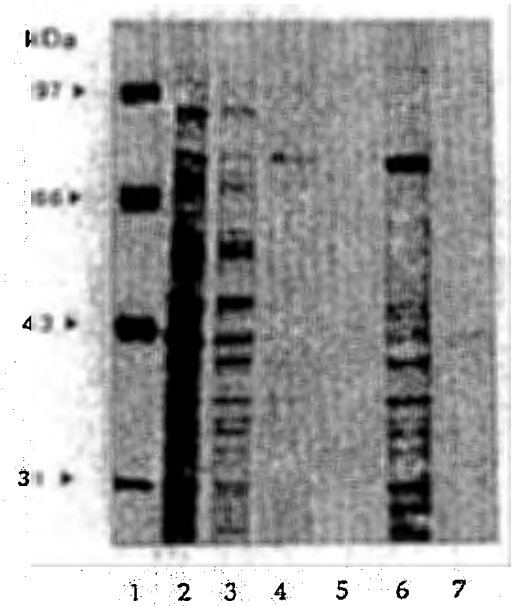

Fig. 3. Immunoaffinity purification of the $75 \cdot \mathrm{kDa}$ protein. Detergent-derived cell lysate from U-937 cells was passed over an immunoaffinity column supporting $m A b 119$. Proteins binding to the affinity column were eluted by a $\mathrm{NaCl}$ step gradient and analyzed by gel electrophoresis and subsequent staining with Coomassie blue. Lane 1, molecular weight markers; lane 2, detergent-solubilized U-937 cell membrane preparation; lane 3 , unbound proteins after 16 $\mathrm{hr}$ circulation over the column; lane 4, $300 \mathrm{mM} \mathrm{NaCl}$ eluate; lane 5 , $500 \mathrm{mM} \mathrm{NaCl}$ eluate; lane 6, polyethylene glycol-concentrated 300 $\mathrm{mM}$ eluate; lane 7, polyethylene glycol-concentrated $500 \mathrm{mM}$ eluate.

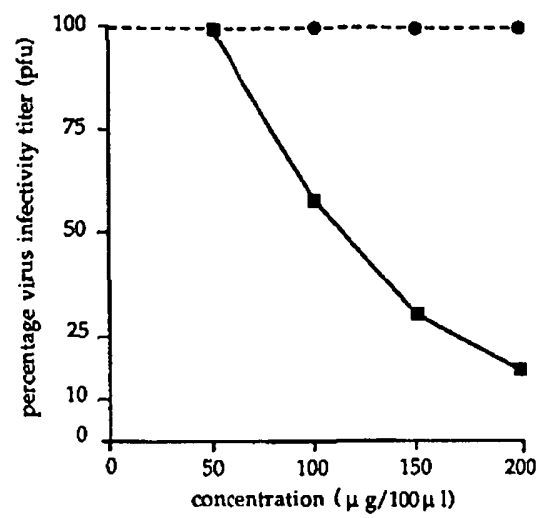

FIG. 4. Reduction of the infectivity of MV after incubation with soluble immunoaffinity enriched $75-\mathrm{kDa}$ protein. The immunoatfinity column-enriched $75-\mathrm{kDa}$ protein and bovine serum albumin (BSA) as control were diluted in PBS to yield a range of concentrations between 0 and $2 \mathrm{mg} / \mathrm{ml}$. Dilutions of MV were mixed with a constant protein concentration and incubated for $1 \mathrm{hr}$ on ice, and residual infectivity was determined by the plaque assay. The results obtained were normalized by setting the infectivity obtained in the presence of BSA to 100\%. The solid line represents MV titrated against the 75 kDa protein, whereas the broken line represents BSA plus MV.

has been maintained. Therefore, the ability of the enriched 75-KDa protein to bind MV was assayed by infection inhibition tests. MV was titrated against constant concentrations of the $75-\mathrm{kDa}$ protein diluted in PBS and incubated for $1 \mathrm{hr}$ on ice. As control, the 75kDa protein was replaced with similar concentrations of bovine serum albumin (BSA). After incubation, the residual infectivity was determined by the standard plaque assay. End-point titration of MV against the purified protein yielded an accurate estimate of the degree of virus binding. A reduction in virus infectivity between 0.95 and $1.1 \log _{10}$ PFU/ml was observed for MV incubated with purified protein of concentration $200 \mathrm{mg} / \mathrm{ml}$ (Fig. 4). This represents an overall loss of MV infectivity due to binding to protein of approximately $90 \%$. Lower concentrations of purified protein gave less dramatic reductions in MV infectivity titer (Fig. 4). Incubation of $M V$ with BSA under the same conditions did not reduce the virus infectivity titer. Likewise, similar assays performed with the morbillivirus CDV revealed no reduction in the virus infectivity titer (data not shown).

\section{Amino acid sequencing of the isolated protein}

$\mathrm{N}$-terminal amino acid microsequencing was performed after separation of the eluted proteins from the mAb 119 immunoaffinity column by SDS-PAGE containing approximately $50-100 \mu \mathrm{g}$ of the $75-\mathrm{kDa}$ protein. The Coomassie-stained $75-\mathrm{kDa}$ band was excised and digested in the gel with protease Lys $C$ and blotted onto Glassybond (Biometra, Göttingen) for sequencing of internal peptides. Three peptides, one at the amino terminus and two internal, were sequenced. 


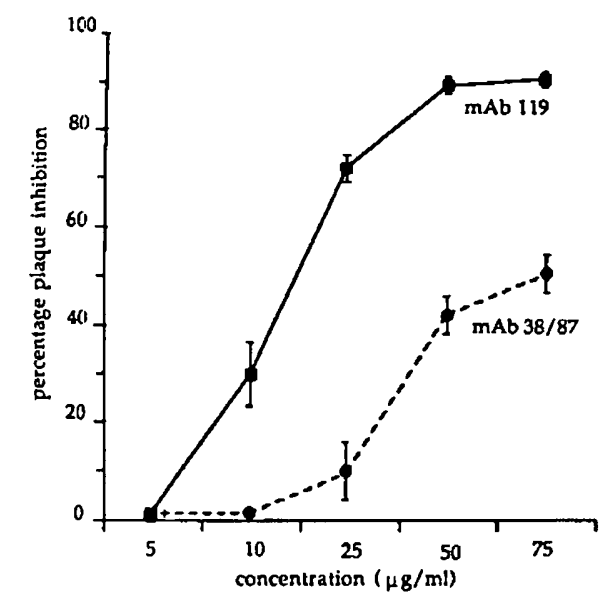

Fig. 5. Dose-dependent inhibition of MV infection after pretreatment of cell monolayers with mAb 119 and mAb 38/87. Vero cell monolayers $\left(1 \times 10^{6}\right.$ cells/well) were incubated with dilutions of mAbs 119 and $38 / 87$ in PBS as indicated and washed with PBS prior to infection vith MV. The percentage of inhibition of plaque formation was plotted against the concentration of mAbs 119 (solid line) and $38 / 87$ (broken line). Mean values of three experiments with standard deviations are shown.

Comparison of the sequences of the peptides with the sequences available in the EMBL data base showed that all three peptides were identical to peptides of the cloned human protein moesin (membrane-organizing extension spike protein, Lankes and Furthmayer, 1991). The peptides correspond to amino acids 1-8 (PKTISVRV), 132-137 (KYGDFN), and 500-513 (KDRSEEERTTEAEK) of human moesin which is comprised of 576 amino acids in total with a calculated molecular mass of $67 \mathrm{kDa}$.

\section{Inhibition of MV infection by moesin-specific antibodies is dose dependent}

To confirm the data obtained with $\operatorname{mAb} 119$, the moesin-specific mAb 38/87 was included in subsequent experiments. The inhibition of MV infection following treatment of cell monolayers with mAbs 119 or $38 / 87$ was determined using the plaque inhibition assay. Half-maximal inhibition of MV infection on Vero cells was achieved after treating cell monolayers with approximately $15 \mu \mathrm{g} / \mathrm{ml}$ of $\mathrm{mAb} 119$ (45\% plaque inhibition), while maximal inhibition was observed with $\geqslant 50$ $\mu \mathrm{g} / \mathrm{ml}(\geqslant 90 \%$ plaque inhibition) of the mAb (Fig. 5). Comparable results were obtained when the assay was performed on other human cell lines (data not shown). A similar dose-dependent curve, albeit much reduced in comparison to the data for $m A b 119$, was observed with the moesin-specific antibody $\mathrm{mAb} 38$ / 87. Half-maximal inhibition of $M V$ infection with this antibody was achieved with $30 \mu \mathrm{g} / \mathrm{ml}$ (27\% plaque inhibition) while maximal inhibition required $90 \mu \mathrm{g} / \mathrm{ml}$ (54\% plaque inhibition; Fig. 5). Our data show that mAb 119 and $\mathrm{mAb} 38 / 87$ recognize different epitopes on moesin, $m A b 38 / 87$ recognizing a linear epitope detected in Western blot as described (Lankes et al., 1988). whereas mAb 119 recognizes a conformational epitope.

\section{Distribution of the epitopes on MV susceptible cell} lines and primary cells

The expression of the epitopes recognized by mAbs 119 and $38 / 87$ on the surface of human primary PBMC and various human and nonhuman cell lines was investigated by flow cytometry. The percentage of cells stained with mAb 119 above the negative control, following labeling with a fluorescein-conjugated second antibody, varied between 40 and $98 \%$ for the human cells examined (Fig. 6). The African green monkey kidney cells (Vero), which are routinely used to propagate MV, were positive to approximately $50 \%$ (Fig. 6). In comparison, mAb 38/87 exhibited a different staining pattern. For each cell line tested, the level of expression of the mAb 38/87 epitope was much reduced, varying between 14 and $38 \%$ (Fig. 6). These results correlate well with the reduced ability of mAb 38/87 to inhibit MV infection in the infection inhibition test (Fig. 5). In contrast to the surface staining of cells, every cell

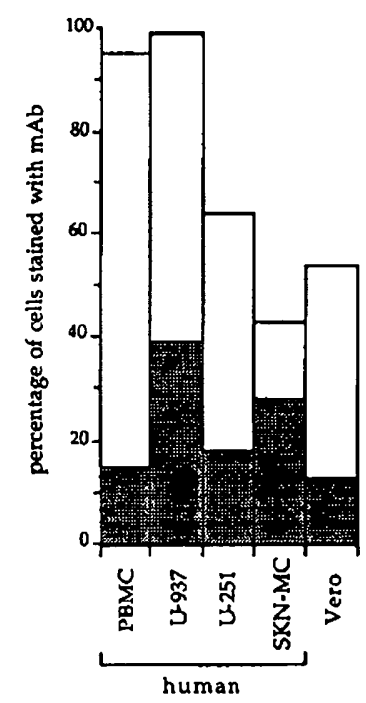

Fig. 6. Distribution of the epitopes of mAbs 119 and $38 / 87$ on the surface of human and monkey cell lines. Flow cytometry was used to determine the distribution of the epitopes recognized by mAb 119 and $\mathrm{mAb} 38 / 87$ on the surface of a number of different cell lines. The $Y$ axis shows the percentage of cells stained above background, the open boxes representing values for mAb 119 and the shaded boxes mAb 38/87. Peripheral blood mononuclear cells (PBMC) and U-937 monocytes revealed the highest levels of surface moesin expression detected by mAb 119, whereas U-251 cells (astrocytoma), SKN-MC cells (neuroblastoma), and Vero cells (African green monkey kidney) expressed the epitope for mAb 119 to a lesser extent. 
of the cell lines investigated so far strongly expresses moesin intracellularly with equal intensities detected with either mAb 119 or mAb 38/87 (data not shown).

\section{Inhibition of MV binding to cells}

In order to investigate the question of whether moe. sin is involved in the attachment of MV to cells, mAbs $38 / 87$ and 119 were tested in rosetting assays for their ability to inhibit MV binding to monkey red blood cells. Incubation of U-937 cells with mAb $38 / 87$ led to $52 \pm$ $3 \%$ reduction in the number of rosettes whilst mAb 119 gave $67 \pm 5 \%$ reduction in rosette formation when compared to control mAbs W6/32 $(9 \pm 2 \%)$ and nonbinding $\cup 85(0 \pm 0 \%)(n=3)$.

\section{Inhibition of vaccinia virus MV-H/F-mediated fusion}

The MV-H and - $\mathrm{F}$ glycoproteins are both required for fusion activity of cellular membranes (Wild et al., 1991). In the rapid screening for new antibodies we found that mAb 119 inhibited fusion of recombinant vaccinia virus MV-H/F-infected U-251, Hela, and Vero cells (not shown). In addition, mAb 38/87 inhibited fusion of vaccinia virus MV-H/F-infected U-251 cells (Fig. 7). Hela, and Vero cells (not shown). These data suggest that in addition to the epitope recognized by $\mathrm{mAb} 119$, the less accessable cell surface moesin epitope of $\mathrm{mAb}$ $38 / 87$ is also functionally active in inhibition assays of MV fusion.

\section{Downregulation of surface moesin expression on MV-infected cells}

The degree of surface and intracellular expression of moesin in uninfected and persistently MV-infected cells was determined by flow cytometry. Persistently infected U-937 cells revealed a considerable reduction of the signal intensity for surface moesin (Fig. 8A, compare signal 1 and 2). In comparison, the expression of the MV fusion protein (MV-F) was detected exclusively on infected cells (Fig. 8B, signal 1 represents the negative control and signal 2 that of anti-MV-F mAb A504), and the expression of $\mathrm{MHC}$ class I molecules was unaltered following infection (Fig. 8C). The intensity of the intracellular expression of moesin was not affected by the infection with MV (not shown). These data suggest that moesin is downregulated from the surface of infected cells, but unaltered intracellularly.

\section{DISCUSSION}

In this report we have described a $m A b$ ( $m A b$ 119) that is directed against an epitope expressed on the surface of a number of human and primate cells and inhibits the binding of MV to its cell receptor, MV glycoprotein-mediated fusion and, hence, infection of the
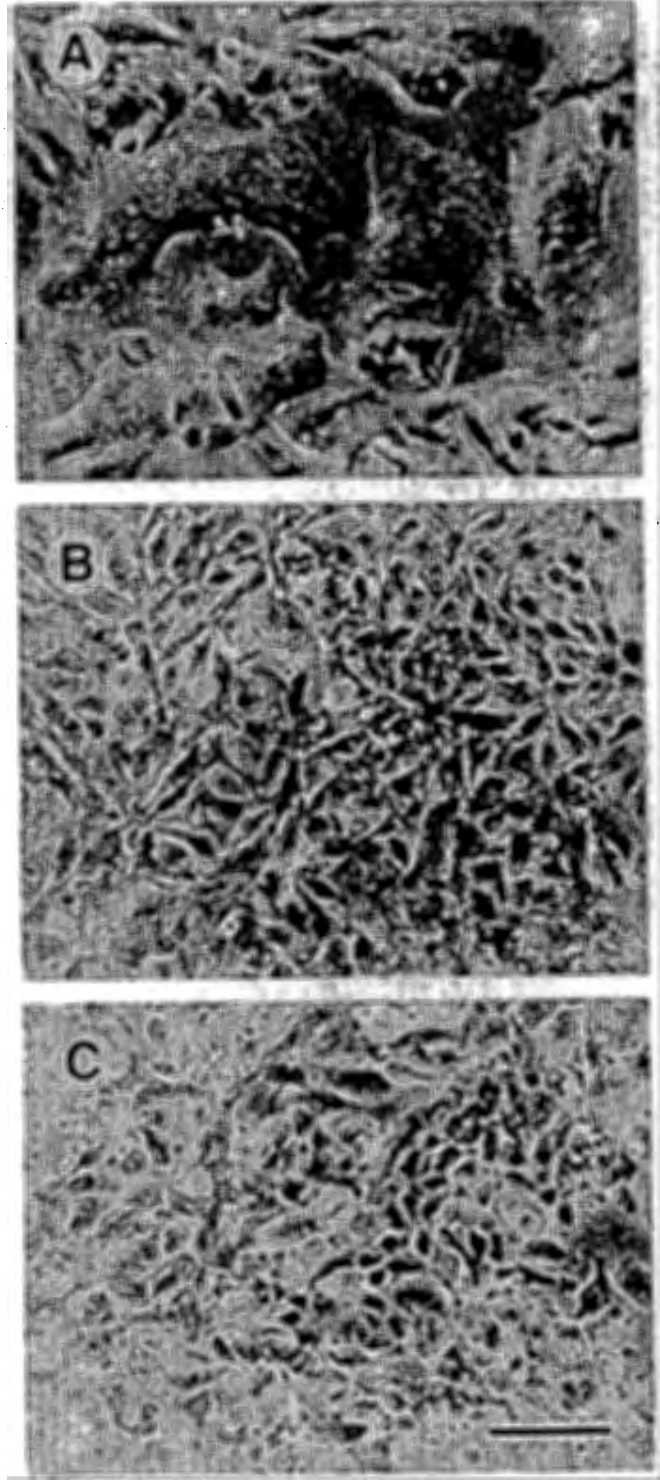

FIG. 7. Inhibition of vaccinia virus MV-H/F-mediated fusion by antibodies to moesin. U-251 cells were infected with a vaccinia virus recombinant expressing $M V-H$ and $-F(m .0 . i .=0.1)$ for $24 \mathrm{hr}$ in the presence of $20 \mu \mathrm{g} / \mathrm{ml}$ of the unrelaied antibody G26 to lymphocyte function-associated antigen (LFA-3) as negative control (A), $20 \mu \mathrm{g} / \mathrm{ml}$ $\mathrm{mAb} 38 / 87$ to moesin (B), and $20 \mu \mathrm{g} / \mathrm{ml} \mathrm{mAb} \mathrm{K} 83$ to $\mathrm{MV}-\mathrm{H}$ as positive control $(C)$. Extensive fusion with large syncytia was observed exclusively in cultures treated with the control antibody (A). Bar, $100 \mu \mathrm{m}$.

normally susceptible cell. The epitope recognized by mAb 119 is widely expressed to high levels on human and primate cells and the antibody was found to specifically inhibit MV infection. The mAb precipitates a 75 . kDa protein, which was identified as the human membrane-organizing extension spike protein, moesin. It is this protein which we believe plays an integral role in the binding and uptake of MV to susceptible cells based on the evidence in this study. 

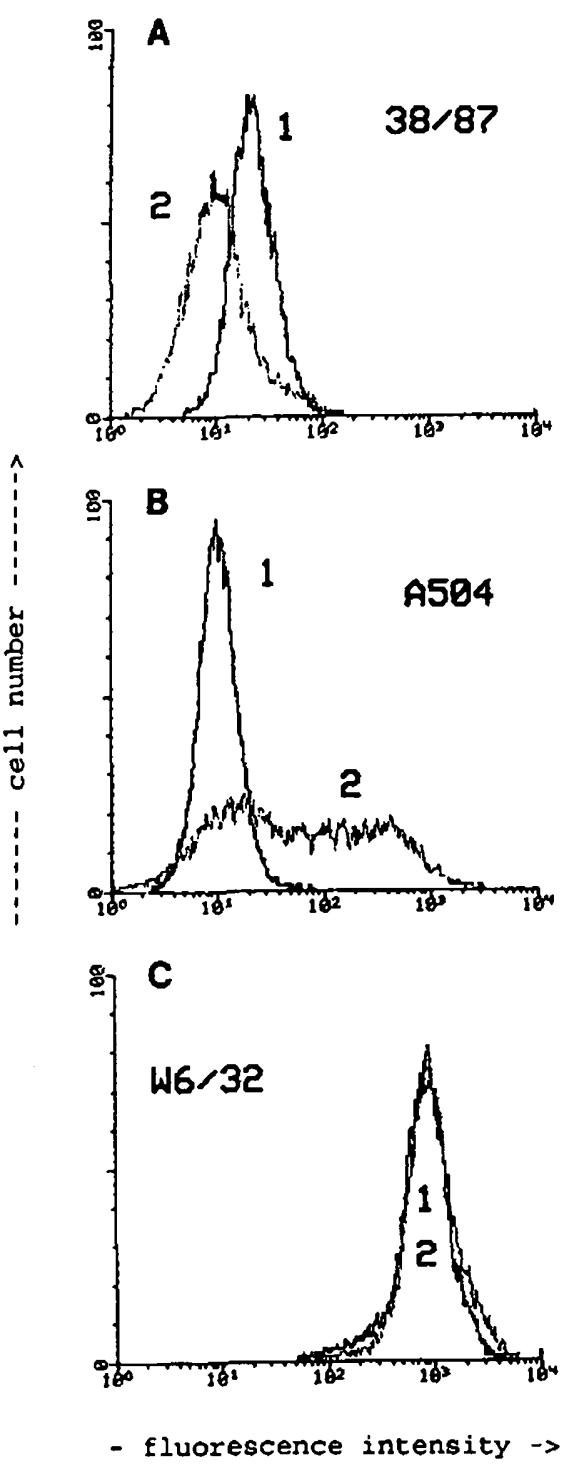

Fig. 8. Downregulation of surface moesin expression after infection of cells with MV. The intensity of the surface expression of moesin on uninfected U-937 cells (signal 1) and U-937 cells persistently infected with MV (signal 2) was measured by flow cytometry. Cells were stained with $\mathrm{mAb} 38 / 87$ to moesin (A), with $\mathrm{mAb} A 504$ recognizing MV-F as a control of infection (B), and with $\mathrm{MAb} W 6 / 32$ to MHC class I as a control for the staining procedure (C). The cell number ( $Y$ axis) was plotted against the fluorescence intensity $X X$ axis).

Recently, a glycoprotein with the mass of $57 / 67 \mathrm{kDa}$ was identified with the aid of a monoclonal antibody as a putative MV receptor (Naniche et al., 1992). This molecule has been identified as the human membrane cofactor protein (CD46) present on many cells of human origin (Naniche et al., 1993b). The described antibody, $\mathrm{MCl} 20.6$, recognizing CD46, inhibits $M V$ binding in a rosetting assay, reduces infection of HeLa cells by MV, and inhibits cellular fusion mediated by vaccinia virus- expressed MV-H and -F proteins (Naniche et al., 1992): $M V$ infection also led to the downregulation of CD46 on the cell surface and moreover, it was found that the $\mathrm{MV}-\mathrm{H}$ protein was responsible for this phenomenon (Naniche et al., 1993a). Since specific receptor downregulation following infection has been observed for several viruses with differing receptor molecules, this finding, in addition to our own observation concerning the downregulation of moesin, add support to the hypothesis that CD46 and moesin act as receptors for MV.

CD46 is known to exist in as many as 14 different isoforms through alternative splicing of the CDNA (Russell et al., 1992) and it is unknown whether or not all these isoforms are able to act as receptor for MV. Indeed, the poliovirus receptor is known to be widely distributed throughout human cell types although the virus is able to infect only a select number of cell types (Ziebert and Wimmer, 1992). It is believed that correct post-transcriptional and post-translational modification of the poliovirus receptor by individual cells is necessary to bind virus (Ziebert and Wimmer, 1992). In the case of MV, cells which do not express human CD46 and are not recognized by CD46-specific antibodies, such as some mouse cell lines, are readily infectable with MV (Rager-Zisman et al., 1984) pointing to the existance of further receptor molecules like moesin, homologs of which are expressed by cells of murine origin.

The protein moesin was initially identified as a cell surface component and thought to act as receptor for binding heparin and heparin sulfate (Lankes et al., 1988). Subsequent cloning of its CDNA and further analysis has revealed that moesin is largely localized at the inner side of the plasma membrane (Lankes et al., 1991). Neither a signal sequence or a transmembrane domain could be identified by sequence analysis, suggesting that it is not incorporated into the plasma membrane in the classical way (Lankes et al., 1991). Following the identification of moesin as the protein precipitated by mAb 119 , we acquired a mAb (38/87) specific for the protein moesin that was used to characterize this protein (Lankes et al., 1988, 1991). From the outset it was known that these two mAbs recognized very different epitopes of the protein moesin. By FACS analysis, the epitope of MAb 119 was found to be widely distributed on the surface of human and primate cells, whereas the epitope of mAb 38/87 was detected to a much lower degree on the surface of cells (Fig. 7). Importantly, by Western blot analysis, only mAb 38/87 is able to detect moesin, suggesting that mAb 119 recognizes a conformational epitope. Crucial evidence supporting the hypothesis that moesin is acting as a receptor for $M V$ came from the ability of $m A b 38 / 87$ to inhibit MV infection of susceptible cells. Moreover, this $\mathrm{mAb}$ inhibited cell fusion following infection with recombinant vaccinia-expressed $\mathrm{MV}-\mathrm{H}$ and $-\mathrm{F}$ protein, 
and inhibited rosette formation by MV and by flow cytometric analysis was downregulated on MV-infected cells, similar to that observed with the putative MV receptor CD46 (Naniche et al., 1993a). The above criterion fulfill the basic requirements for receptor blocking activity and mirrors the results obtained with mAb 119 . The level of infection inhibition by mAb 38/87 was somewhat less than that observed with $\mathrm{mAb} 119$ and can be correlated to the accessability of the epitopes for each specific antibody on the surface of cells. As mentioned earlier, moesin is mainly localized on the internal side of the cell membrane which becomes apparent when cells are permeabilized prior to staining with antibodies. It is possible that the mode by which mAb 38/87 inhibits MV binding is by blocking MV access to the conformational mAb 119 site following attachment to its cell surface-expressed motif. This is currently being investigated.

A further important observation that points to moe$\sin$ as a putative receptor for MV is based on the observation that the purified protein binds MV itself. This is not unusual given that, for example, soluble CD4 has been shown to inhibit the infection of certain cell types with HIV (Orloff et al., 1993). Interestingly, in the case of HIV, alternative receptors which are not inhibitable by soluble CD4 can be used in the brain and by muscle cells (Clapham et al., 1989). In addition, the results presented in this study point to the fact that more than one molecule is likely to be acting as receptors for $\mathrm{MV}$. To gain entry into cells, MV utilizes two major protein species, the $\mathrm{H}$ and $\mathrm{F}$ proteins, and both are required for fusion of cells (Wild et al., 1991). It may be that the initial receptor interaction is mediated by a single specific receptor species with $M V-H$, followed by contact of the virus with a second receptor ( $F$ interaction) to initiate successful infection. Our data show that there is a specific interaction between MV and moesin and that the critical motif is conformational and expressed on the cell surface. The question of whether moesin and CD46 are alternative receptors or part of one receptor complex is currently under investigation.

Moesin, as well as its homologs of the ERM (ezrinradixin-moesin) gene family have been shown to be localized at cell-to-cell adherens junctions, cleavage furrows, microvilli, and ruffling membranes (Sato et al., 1992). Most intense staining was found at the cleavage furrows in the mitotic phase of the cell cycle and could point to a correlation with the cell cycle dependence of infection with MV. Furthermore, the concentration of ERM proteins at cell-to-cell adhesion junctions and cleavage furrows and their interaction with actin (Sato et al., 1992), mediating the association of actin filaments with the plasma membrane, suggest a direct connection between actin filaments and MV. How moesin is involved in the attachment and uptake of $\mathrm{MV}$ is an intriguing question which is under investigation.

\section{ACKNOWLEDGMENTS}

We thank Sibylle Schneider-Schaulies for helptul discussions and Katerina Pech for technical assistance. This work was supported by grants from the Deutsche Forschungsgemeinschaft and the Bundesministerium für Forschung und Technologie. L. M. Dunster is a research fellow of the Alexander von Humboldt Foundation.

\section{REFERENCES}

Casali, P., Nakamura, M., and McChesney. M. B. (1989). Immunosuppression by measles virus. In "Virus Induced Immunosuppression" (S. Spector, M. Bendinelli, and H. Friedmann, Eds.). Chap. 18. pp. 345-373. Plenum Press, NY/London.

Clapham, P. R., Weber, J. N., Whitby, D., MCINTOSH, K., DAlgeish, A. G., Maddon, P. J., Deen, K. C., Sweet, R. W., and Weiss, R. A. (1989). Soluble CD4 blocks the infectivity of diverse strains of HIV and SIV for T cells and monocytes but not for brain and muscle cells. Nature 337, 368-370.

DVeskler, G. S., Dieffenbach, C. W. CARDewChio, C. B., McCuaig, K., Pensiero, M. N., Jiang, G-S., Beauchemin, N., and Homes, K. V. (1993). Several members of the mouse carcinoembryonic antigenrelated glycoprotein family are functional receptors for the coronavirus mouse hepatitis virus A59. J. Virol. 67, 1-8.

ECKERSKORN, C., and LoTrSPEICH, F. (1989). Internal amino acid sequence analysis of proteins separated by gel electrophoresis after tryptic digestion in a polyacrylamide matrix. Chromatographia 29, 92-94.

ECKERSKORN, C., MEWES, W., GORETZKI, H., and LOTTSPEICH, F. (1988) A new siliconized-glass fiber as a support for protein-chemical analysis of electroblotted proteins. Eur. J. Biochem. 176, 509519.

Esiri, M. M., Oppenheimer, D. R., Brownell, B., and Haire, M (1981). Distribution of measles antigen and immunoglobulin containing cells in the CNS in subacute sclerosing panencephalitis (SSPE) and atypical measles. J. Neurol. Sci. 53, 29-43.

haAse, A. T., Gantz, D., Eble, B., Walker, D., Stowing, L., Ventura, P., Blum, H., Wietgrefe, S., Zupanicic. M., and Tourtellotte, W. (1985). Natural history of restricted synthesis and expression of measles virus genes in subacute sclerosing panencephalitis. Proc. Natl. Acad. Sci. USA 82, 3020-3024.

harouse, J. M., Bhat, S., Spitalnik, S. L., Laughlin, M., Stefano, K., SilberberG, D. H., and Gonzales-Scarano, F. (1991). Inhibition of entry of HIV- 1 in neural cell lines by antibodies against galactosyl ceramide. Science 253, 320-323.

harouse, J. M., Kunsch, C., Hartle, H. T., laughlin, M. A., Hoxie, J. A., Wigdahl, B., and Gonzales-Scarano, F. (1989). CD4-independent infection of human neural cells by human immunodeficiency virus type 1. J. Virol. 63, 2527-2533.

harrowe, G., Mitsuhashi, M., and Payan, D. G. (1990). Measles virus-substance $P$ receptor interactions. J. Clin. Invest. 85, 13241327.

Harrowe, G., Sudduth-Klinger, J., and Payan, D. G. (1992). Measles virus-substance $P$ receptor interaction: Jurkat lymphocytes transfected with substance $P$ receptor cDNA enhance measles virus fusion and replication. Cell. Mol. Neurobiol. 12, 397-409.

KiRK, J., Zhou, A. L., MCQuaid, S., Cosby, S. L., and Allen, I. V. (1991). Cerebral endothelial cell infection by measles virus in subacute sclerosing panencephalitis: Ultrastructural and in situ hybridization evidence. Neuropathol. Appl. Neurobiol. 17, 289-297.

KRAH, D. L. (1989). Characterization of octyl-glucoside-solubilized cell membrane receptors for binding measles virus. Virology 172 386-390. 
KRAH, D. L. (1991). Receptors for binding measles virus on host cells and erythrocytes. Microbial Pathogen. 11, 221-228.

LANKES, W. T., and FURTHMAYER, H. (1991). Moesin: A member of the protein 4.1-talin-ezrin family of proteins. Proc. Natl. Acad. Sci. USA 88, 8297-8301.

Lankes, W. T., Griesmacher, A., Grünwald, J., Schwartz-Allbiez, R., and KELLER, R. (1988). A heparin-binding protein involved in inhibition of smooth muscle cell proliferation. Biochem. J. 251, 831842.

LENTZ, T. L. (1990). The recognition event between virus and host receptor: A target for antiviral agents. J. Gen. Virol. 71, 751-766.

Moench, T. R., Griffin, D. E., Obriecht, C. R., Vaisberg, A., and JOHNSON, R. T. (1988). Distribution of measles virus antigen and RNA in acute measles with and without neurologic involvement. $/$. Infect. Dis. 158, 433-442.

Naniche, [1., Wild. T. F., Rabourdin-Combe, C., and Gerlier, D. (1992). A monoclonal antibody recognizes a human cell surface glycoprotein involved in measles virus binding. J. Gen. Virol. 73, 2617-2624.

Naniche, D., Wild, T. F., Rabourdin-Combe, C., and Gerlier, D. (1993a). Measles virus haemagglutinin induces down-regulation of gp57/67, a molecule involved in virus binding. J. Gen. Virol. 74, 1073-1079.

Naniche, D. Varior-Kishnan, G., Cervoni, F., Wild, T. F., Rossi, B., RABOURDIN-COMBe, C., and GerLier, D. (1993b). Human membrane cofactor protein (CD 46) acts as a cellular receptor for measles virus. J. Virol., 67, 6025-6032.

Orloff. S. L., Kennedy, M. S., Belperron, A. A., Maddon, P. J., and MCDougaL, J. S. (1993). Two mechanisms of soluble CD4 (sCD4)mediated inhibition of human immunodeficiency virus type 1 (HIV1) infectivity and their relation to primary HIV- 1 isolates with reduced sensitivity to SCD4. J. Virol. 67, 1461- $\$ 471$.

Rager-Zisman, B., Egan, J. E., Kress, Y., and Bloom, B. R. (1984).
Isolation of cold-sensitive mutants of measles virus from persistently infected murine neuroblastoma cells. J. Virol. 51, 845-855.

Russell, S. M., Sparrow, R. L., MCKenzie, I. F. C., and Purcell, D. F. J. (1992). Tissue specific and allelic expression of the complement regulator CD 46 is controlled by an alternative splicing. Eur. J. Immunol. 22, 1513-1518.

Sato, N., funayama, N., Nagafuchi, A., Yonemura, S., Tsukita, S., and TSUKITA, S. (1992). A gene family consisting of ezrin, radixin and moesin. J. Cell Sci. 103, 131-143.

SChNeider-SChaulies, J., Schneider-Schaulies, S., Brinkmann, R., Tas, P., Halbrügge, M., Walter, U., Holmes, C., and ter Meulen, V. (1992). HIV-1 gp120 receptor on CD4-negative brain cells activates a tyrosine kinase. Virology 191, 765-772.

SCHNeider-SChaulies, J., SChneider-Schaulies, S., and ter MeUlen, $V$. (1993). Differential induction of cytokines by primary and persistent measles infections in human glial cells. Virology 195, 219228.

SCHNEIDER-SCHAULIES, S., and TER MEULEN, V. (1992). Molecular aspects of measies virus induced central nervous system diseases. In "Molecular Neurovirology" (R. P. Roos, Ed.), pp. 419 449. Humana Press Inc., Clifton, NJ.

WHITE, J. M., and LITTMAN. D. R. (1989). Viral receptors of the immunoglobulin superfamily. Cell 56, 725-728.

WILD, T. F., MALVOISIN, E., and BUCKLAND, R. (1991). Measles virus: Both the haemagglutinin and fusion glycoproteins are required for fusion. J. Gen. Virol. 72, 439-442.

Yoshikawa, Y., Yamanouchi, K., Takasu, T., Rauf, S., and Ammed, A (1991). Structural homology between hemagglutinin (HA) of measles virus and the active site of long neurotoxins. Virus Genes 5, 57-67.

ZiEBERT, A., and WIMMER, E. (1992). N-glycosylation of the virus binding domain is not essential for function of the human poliovirus receptor. J. Virol. 66, 7368-7373. 